\title{
Methodo para diagnostico do alastrim *
}

\author{
pelos \\ Dis. C. Magarinos Torres e J. de Castro Teixeira
}

(Com 3 estampas)

Alé agora, o dragnostico diflerencial entre variola e alastrim tem sido ponto de controversia por parte das auloridades sanitarias no Brasil.

Nestes ultimos annos lem prevalecido a doutrina segundo a qual as duas doenças seriam identicas. Como consequencia, encontramos registradas como epidemias de variola as que occorreram na cidade do Rio de Janeiro, em 1932 (v. Bol. Estatist. Demogr. Sanit. Cid. Rio Jan., 1932, 12 : 47) e na de S. Paulo, em 1936.

Esse facto significa, apenas, a difficuldade que o sanitarista encontra, em realizar um diagnostico differencial, baseado em dados objectivos constantes e seguros. É sabido que a evolução clinica e os documientos epidemiologicos não bastam para resolver a questão. Por outro lado, a reacção da cornea do coelho apresenta difficuldade de inlerprelação. Os resultados alcançados com esse methodo de diagnostico só poderão ser proveitosamente utilisados por quem tiver experiencia prévia do processo applicado ao estudo dos virus da variola vera, da vaccina e do alastrim.

Queremos, assim, dizer que até o presente, no Brasil, os diagnosticos de variola e de alastrim tem sido mais a consequencia da doutrina que o sanitarista adopta, no momento, do que uma conclusão baseada em dados colhidos para o caso concreto.

Em trabalhos anteriores (Torres \& Teixeira 1933, 1934 e 1935, e Torres 1936) descrevemos a morphologia das inclusões cellulares do alastrim, em cellulas epidermicas do homem e do Macaca mulatta, comparanda-as com as da variola vera e as da vaccina.

Chegamos ao resultado de que era possivel estabelecer dislincções quanto á localisação, fórma, dimensões e propriedades tinctoriaes das inclusões cellulares especificas, em taes affecções.

* Recebido para publicação a 25 de Agosto de 1937 e dado á publicidade em Dezembro de 1937. 
As figuras 1-8, Estampa 1, resumem taes conclusões, e nos dispensam de insistir nesse ponto.

Restava, comludo, esclarecer se as inclusões do alastrim se apresentaram, sempre, com identico aspecto e propriedades tincloriaes, em epochas differentes e qualquer que fôsse o fóco da doença estudado.

O presente trabalho procura esclarecer esse ponto, aproveitando material colhido em sete fócos epidemicos differentes.

Utilisando da experiencia que adquirimos, procuramos estatuir um mothodo de laboratorio que désse resultados seguros e constantes, de modo a fornecer ao sanitarista, bases concretas em que apoiar o seu diagnostico.

\section{EPIDEMIAS DE ALASTRIM ESTUDADAS}

1. - Fóco occorrido na cidade de Belém, Eslado do Pará regiäo Norte do Brasil), em Setembro de 1936.

Segundo informações do Dr. Acalauassú Nunes filho, Director da Saúde Publica do Estado do Pará, o surto epidemico constou de cerca de 300 casos com um obito.

O material. que nos foi gentilmente remettido pelo Dr. Acatauassú Nunes filho, consta de fragmentos de pustulas reliradas por biopsia, de um doente, e conservadas em glycerina pura.

Colhido a 13 de Setembro, foi o material, apenas recebido $\mathrm{cm}$ nosso laboratorio, triturado com agua physiologica esteril e inuculado, por via endovenosa, a um macaco rhesus adulto (n. ${ }^{\circ} 2425$ ). Este apresentoli febre, no setimo dia, e erupcão cutanea, no oitavo para nono dias, com predominancia nos membros superiores, especialmente na região plantar (Fig. 10). O macaco sobreviveu.

Em biopsia de uma vesicula retirada no sexto dia de inoculação, verificamos a presença de inclusões cytoplasmaticas, juxta-nucleares, basophilas, não coraveis pela safranina, (Fig. 13), identicas ás que anteriormente descreveramos no alastrim.

2. - Fóco occorrido na cidade de São Paulo, Estado de São Paulo (região Sul do Brasii), duranle o anno de 1936.

Informações detalhadas sobre este surto epidemico nos foram gentilmente fornecidas pelo Dr. Calazans, Director Geral do Serviço Sanitario de São Paulo, e pelo Dr. Synésio Rangel Pestana, Directo! clinico da Santa Casa de Misericordia da Capilal do Estado de São Paulo, aos quaes agradecemos.

A epidemia, officialmente notificada como variola, constou de 186 casos e nenhum obito. Teve origem na Santa Casa de Misericordia, em 
un individuo que viera do interior do Estado. Nessa occasião existiam fócos epidemicos em diversos municipios, entre outros, nos de Juquery, Jundiahy, Alibaia e Bragança.

No periodo comprehendido entre Janeiro e Dezembro de 1936, as notificações de "variola recebidas pelas Delegacias de Saúde do interior do Estado de São Paulo, foram em numero de 1.089, sendo os casos assim distribuidos, de accôrdo com as cidades:- Campinas, 119 casos, Baurú, 401 casos, Ribeirão Prelo, 172 casos, Botucalú, 32 casos, Guaratinguetá, 22 casos, São Carlos, 12 casos, e Santos, 1 caso. Alguns casos, vistos pelo Prof. Dr. Flavio da Fonseca, em Dezembro de 1936, no Hospital de Isolamento da cidade de São Paulo, apresentavam erupção confluente, sendo, no entanto, bom, o estado geral dos doentes. O material, que nos foi por elle gentilmente enviado, consta do conteúdo de pustulas de dois doentes, conservado em pipelas capillares estereis.

Com o material de um delles doente B. B., registro 506, Pavilhão 4), colhido no decimo terceiro dia de doença, inoculamos um macaco rhesus, femea, jovem (n. ${ }^{\circ} 2493$ ). Fste apresentou elevação thermica e erupção vesico-pustulosa no selimo dia de inoculação. As lesões entraram em dissecação, no decimo primeiro dia. Eram predominantes na face (lig. 11) e membros inferiores (Fig. 12). O animal soloreviveu.

Foram feilas tres biopsias de lesões culaneas, respeclivamente no oilavo, nono e decimo dias de inoculação. O seu estudo histologico mostra accentuada hyperacanthose e espongiose em fócos multiplos, iniciando a formação de vesiculas. Embora em phase precoce de evolução, as efflorescencias culaneas experimenlaes mostram, no derma, pronunciada infiltração cellular. As cellulas malpighianas, no fundo e margens das lesões, contèm numero consideravel de inclusões cytoplasmaticas lypicas do alastrim (Fig. 14), bem como inclusões nucleares (Fig. 16 .

3. - Fóco occorrido na cidade de Ilaperuna, Estado do Rio de Janciro (região Sul do Brasil), em 1933.

Não foram publicadas informações sobre o numero de casos, caracterisando-se a epidemia, por baixo indice de mortalidade.

Graças á gentileza do Dr. Americo Oberlaender, Director de Saúde Publica do Estado do Rio de Janeiro, pudemos estudar um doente, o qua! foi transporlado do fóco epidemico para o Hospilal annexo ao Instilute Oswaldo Cruz.

Com material retirado de diversas vesico-pustulas, e emulsionado em agua physiologica, inoculamos, por via endovenosa, um macaco rhe- 
sus (11." 4060), o qual apresentou febre, no sexlo dia de inoculação, persistindo nos tres dias immediatos, e uma erupção vesico-pustulosa, iniciada no sexto dia. O animal sobreviveu.

Numerosas inclusões cytoplasmaticas basophilas, juxla-nucleares, não coraveis pela safranina, com a morphologia e reacções corantes das inclusões do alastrim, são encontradas em cellulas epidermicas das margens e fundo de uma vesico-pustula retirada, por biopsia, no sexto dia de inoculação.

4. - Fóco occorrido na cidade de Caratinga, Estado de Minas Geraes (região central do Brasil), em Julho e Agosto de 1933.

Não foram publicadas informações officiaes sobre o numero de casos occorridos. A epidemia caracterisa-se por baixo indice de mortalidade.

O malerial consta do conteúdo de vesico-pustulas de dois doentes, colhidos em tubos capillares esterelisados, o qual nos foi, gentilmente, enviado pelo Dr. Jairo Lobo Martins, clinico naquella cidade.

Dois macacos rhesus (nos. 1577 e 1593), foram inoculados por via endovenosa, um a 13 de Julho, com material colhido a 9 de Julho, e outro a 9 de Agosto, com material colhido a 3 de Agosto. Ambos apresentaram elevação thermica no quinto para o sexto dias de inoculação, e uma erupção vesico-pustulosa, a qual predomina nos membros inferiores. Ambos sobreviveram.

Inclusões cytoplasmaticas typicas do alastrim, juxta-nucleares, basophilas, não coraveis pela safranina, existiam em cellulas epidermicas de uma vesico-pustula do primeiro macaco, retirada por biopsia, (n.' 3904), no sexto dia de inoculação.

5. - Fóco occorrido na cidade de Bello Horizonte, Estado de Minas Geraes (região central do Brasil), em Setembro de 1933.

Não foram publicadas informacoes sobre o numero tolal de casos, tendo sido registrados tres obitos com o diagnoslico de variola no Bol. Estatist. Dem. Sanit. Cid. Rio de Janeiro, 1933, 12 : 219.

(1 material, gentilmente fornecido pelo Dr. Ernani Agricola, Director de Saúde Publica Estadoal, consta do conteúdo de varias pustulas, conservado em glycerina a $50 \%$. Colhido a 1 de Setembro, foi o material, préviamente emulsionado em agua physiologica, inoculado por via endovenosa, a 12 de Setembro, em um macaco rhesus adulto $\left(n .^{\circ}\right.$ 1597). O protocollo deste animal menciona elevação thermica no quinto dia de inoculação, e apparição, no sexto dia, de numerosas vesiculas nas extremidades dos membros (Fig. 9). e, em menor numero, na face. $\mathrm{O}$ animal sobreviveu. 
Inclusões cytoplasmaticas juxta-nucleares, basophilas, não coraveis pela safranina, eram muilo numerosas em cellulas epidermicas de uma papula (Fig. 15) retirada no sexto dia de inoculação.

6. - Fóco occorrido na cidade do Rio de Janeiro (região Sul do Brasil), em 1932.

A epidemia constou de pequeno numero de casos registrados no Boletin: Mensal da Estatistica Demographo-Sanitaria da Cidade do Rio de Janeiro, 1932, 12:47, sob as epigraphes de variola (32 casos); e alastrim ( 3 casos), aos quaes é preciso acrescentar mais oito por nós observados em tropa aquartellada e isolados no Hospital annexo ao Instituto Oswaldo Cruz. Apenas um obilo foi registrado.

Em oito doentes praticamos biopsias de lesões cutaneas, nellas encontrando inclusões cyloplasmalicas, juxla-nucleares, basophilas, não coradas pela safranina, em cellulas epitheliaes das margens das vesiculas e vesico-pustulas. Inclusões com caracteres morphologicos e tinctoriaes semelhantes foram obtidas em dois macacos rhesus inoculados, por via endovenosa, com material dos doentes. Tendo sido esse material aproveitado em trabalho anterior (Torres \& Teixeira 1934a, Figuras 1-18, Estampa 28. Figuras 19-23, Estampa 29, e Figuras 33-38, Estampa 30), dispensamo-nos de maiores considerações a respeito.

7. - Fóco de alastrim occorrido na cidade do Rio de Janeiro (região Sul do Brasil), em 1937.

Com o conteúdo de vesico-pustulas de dois casos isolados na Enfermaria 18 do Hospital São Francisco de Assis, Serviço do Professor Dr. J. Moreira da Fonseca, inoculamos por via endovenosa, dois macacos rhesus, os quaes apresentaram os symptomas habituaes do alastrim experimental.

Inclusões cytoplasmaticas, juxta-nucleares, basophilas, não coradas pela safranina, foram evidenciadas em cellulas epidermicas de lesões culaneas retiradas por biopsias, respectivamente, no quarto dia de erupção e nono de inoculação, em um macaco, e no terceiro de erupção e oitavo de inoculação, em outro.

\section{METHODO PROPOSTO}

Baseia-se na sensibilidade que apresenta um animal de laboratorio, o macaco rhesus (Macaca mulatta), ao virus do alastrim, e no aspecto typico que revestem as inclusões cellulares especificas, nas cellulas epjidermicas das lesões experimentaes.

Quer as inclusões cyloplasmaticas, quer as nucleares são muilo 
semelhantes ás vistas em casos humanos de alastrim, sendo nilidamente differentes, pela sua morphologia, e, especialmente, pelas suas reacções corantes (Figs. 1-8, Fst. 1) das conseguidas, na mesma especie de macaco, com o virus da vaccina, e das encontradas em casos humanos de variola vera.

1. Colher o material no doente suspeito, aspirando o conteúdo de vesiculas ou de vesico-pustulas, préviamente desinfecladas com alcool, em pipelas capillares esterelisadas. A colheita é praticada, ordinariamente, entre o segundo e o decimo dias de erupção, mais commummente entre o quarto e o nono dias, quando o exanthema se apresenta em franca evolução, e o doente é posto em contacto com as autoridades sanitarias. As pipetas, convenientemente accondicionadas, são remeliidas ao laboratorio. Uma demora até de quinze dias no transporte, não traz sérios prejuizos ao resultado do methodo, embora seja preferivel, naturalmente, usar material tanto mais recente quanto possivel

2. - O material recebido no laboratorio é diluido em sôro physiologico, e inoculado, por via endo-venosa, em um macaco rhesus. A inoculação é feita, com facilidade, nas veias da face interna dos membros inferiores. O animal infecta-se, de modo constante, apresentando symplomatologia typica, da qual faz parte um exanthema assaz semelhante ao da doença humana (Figs. 9 e 10 ); sobrevive á infecção, resistindo bem ás biopsias praticadas.

3. - Retirar, por biopsia, lesões culaneas do macaco rhesus, quando estas se encontram bem constituidas, o que, de regra, occorre entre o sexto e o nono dias de inoculação. É sufficiente uma simples contenção manual, no momento de praticar as biopsias, bastando, como instrumenlal, tesouras e pinças. A applicação de "agrafes", e desinfecção com tintura de iodo, completam o aclo operalorio. Quando a hemorrhagia é pequena, não é necessario usar de "agrafes", bastando tamponar o ferimento com algodão immerso em collodio. Os fragmentos de lecido são fixados em Zenker-formol, durante 24 horas. Praticar, com lamina cortante fina (lamina de navalha Gillette), um córle perpendicular á superficie da lesão, de modo a obtér córtes histologicos orientádos nesse sentido, e abrangendo, desde logo, a lesão. Inclusão em paraffina.

4 - Coloração dos córtes, da espessura maxima de 6 micra, pelos seguintes methodos:

a) - hematoxylina-eosina, segundo o processo rolineiro.

b) - hematoxylina-safranina, demorando os córtes 10 minulos, na 
hematoxylina de Delafield diluida, 10 minutos em agua corrente, 10 minulos em uma solução aquosa a $1 \%$ de safranina, e 10 minutos em solução aquosa de acido tannico a $25 \%$. Agua. Alcool absoluto. Oleo de bergamota-xylol. Xylol. Balsamo.

Resultado: - Procurar as inclusões cyloplasmalicas especificas, em cellulas epidermicas das margens e fundo da lesão, de preferencia nas que apresentam nucleo bem conservado.

No alastrim, as inclusões cytoplasmalicas são juxla-nucleares, isolacias, ou em polos oppostos do nucleo, coradas em azul-cinzento. nos preparados pela hematoxylina-eosina, e pallidamente em azul, nos pela hematoxylina-safranina. Nestes ultimos, fazem grande contraste com os nucleolos das cellulas, intensamente corados pela safranina.

Em material antigo, embora incluido em paraffina, as inclusões eyloplasmaticas do alastrim coram-se mal pela hematoxylina-safranina, ao passe que os granulos de chromatina, originarios de cellulas necrosadas, e occasionalmente englobados pelas cellulas epidermicas, conservam grande affinidade corante para com a safranina. É essa uma causz de erro que convem estar presente ao microscopista pouco familiarisado com o estudo de inclusões em doenças de virus.

\section{SUMMARY}

Inclusion bodies of alastrim are quile consistent in their morphology and staining properties when studied in material from seven epidemics occurring in several States of Brazil (Pará, Minas Geraes, Rio de Janeiro. Districto Federal and São Paulo from 1932 to 1937.

Paranuclear or circumnuclear basophilic cyloplasmic bodies not stained by safranine, single or in pairs at opposite ends of the nuclei could always be demonstrated in epidermal cells from skin lesions cither in man or in Macaca mulatta. Cytoplasmic inclusion bodies of variola vera as seen in human cases, and of vaccinia as seen in Macaca mulatta are acidophilic or polychromatophilic and deeply slained by safranine.

A method for the diagnosis of alastrim is devised taking into account the sensibility of Macaca mulatta to the virus, and the morphology and staining properties of the cytoplasmic inclusion bodies as seen in skin lesions of the monkey.

This method has been successfully tried in epidemics occurring at the States of Pará (1936), São Paulo (1936) and Districto Federal (1937) when the real diagnosis was a matler of discussion. 


\section{BIBLIOGRAPHIA}

Torres, C. M. \& Teixeira, J. C.

1933 a. Transmission de l'alastrim au Macacus rhesıs. C. R. Soc. Biol., 112 : 917-919.

1933 b. Histologie de l'alastrim chez le Macacus rhesus. C. R. Soc. Biol., 112 : 920-921.

1933 c. Inclusions cytoplasmaliques de l'alastrim chez le Macacus rhesus et chez le Lapin. C. R. Soc. Biol., 112 : 922-924.

1933 d. Étude des inclusions cellulaires de l'alastrim et de la vaccine chez le Singe (Macacus rhesus). C. R. Soc. Biol., 114: 967-968.

1934 a. Estudo comparativo das inclusões do alastrim e da vaccina no macaco (Macacus rhesus). Mem. Inst. Oswaldo Cruz, 28 : 181-203.

1934 b. Diagnostic différential des inclusions cytoplasmatiques de l'alastrim et de la variole. C. R. Soc. Biol., 117 : 505.

1935 a. Sur les inclusions intranucléaires de l'alastrim et de la variole chez l'homme. C. R. Soc. Biol., 118 : 719-720.

$1935 \mathrm{~b}$. Estudo comparativo das inclusions do alastrim e da variola vera. Mem. Inst. Oswaldo Cruz, 30 : 183-240.

Torres, C. M.

1936. Further Studies on the Pathology of Alastrim and their Signilicance in the Variola-Alastrim Problem. Proc. Roy. Soc. Med., London, 29 : 1525-1540.

\section{Estampa 1}

Fig. 1 - Inclusões cytoplasmaticas, solitarias, juxta-nucleares, basophilas, em cellulas epidermicas de Macaca mulatta (n.o 3983), inoculado com alastrim. Coloração: hematoxylina-eosina.

Fig. 2-Inclusões cytoplasmaticas do alastrim em cellulas epidermicas de $M a$ caca mulatta (n.o 3983). Ao passo que os nucleolos coram-se,. intensamente, pela safranina, as inclusões tingem-se pallidamente em azul. Coloração: hematoxylina-safranina.

Fig. 3 - Inclusões cytoplasmaticas, solitarias, juxta-nucleares, basophilas, em cellulas epidermicas de um caso humano de alastrim (n.o 3647). Coloração: hematoxylina-eosina.

Fig. 4-Inclusões cytoplasmaticas do alastrim em caso humano (n. ${ }^{\circ}$ 3647). Nucleolos intensamente corados pela safranina, inclusões em azul pallido. Coloração: hematoxylina-safranina.

Fig. 5-Inclusões cytoplasmaticas, acidophilas, em cellulas da epiderme de um caso humano de variola vera (n. ${ }^{\circ} 3933$ ). Coloração: hematoxylina-eosina.

Fig. 6-- Inclusões cytoplasmaticas em cellulas da epiderme de $\mathrm{um}$ caso humano de variola vera (n.o 3933). As inclusões, assim como os nucleolos, apresentam-se coradas pela safranina. Coloração: hematoxylina-safranina.

Fig. 7 -Inclusões cytoplasmaticas, polychromatophilas, em cellulas da epiderme de Macaca mulatta (n.o 3791) inoculado com vaccina. Coloraçĩo: hematoxylina-eosina.

Fig. 8-Inclusões cytoplasmaticas multiplas, em cellulas da epiderme de $\mathbf{M a}$ caca mulatta (n.o 3791), inoculado com vaccina. As inclusões, assim como os nucleolos, coram-se pela safranina. Coloração: hematoxylinasafranina. 


\section{CYTOPLASMIC INCLUSION BODIES OF ALASTRIM, SMALLPOX AND VACCINIA IN EPIDERMAL CELLS}

- Alastrim in rhesus monkey

Hematoxylin and eosin $\left\{\begin{array}{c}\text { Single } \\ \text { or double } \\ \text { juxta-nuclear } \\ \text { basophilic } \\ \text { bodies }\end{array}\right.$
Alastrim in man

Simallpox in man
Vaccinia in rhesus

monkey

Numerous

polychromato-

philic bodies
Single or double
juxta-nuclear
basophilic
bodies
Numerous rather small acidophilic bodies

\author{
Deeply stained \\ safraninophilic \\ bodies
}

$\begin{array}{cc}\text { Juxta nuclear } & \begin{array}{c}\text { Deeply stained } \\ \text { pale blue }\end{array} \\ \text { safraninophilic } \\ \text { stained bodies } & \text { bodies }\end{array}$



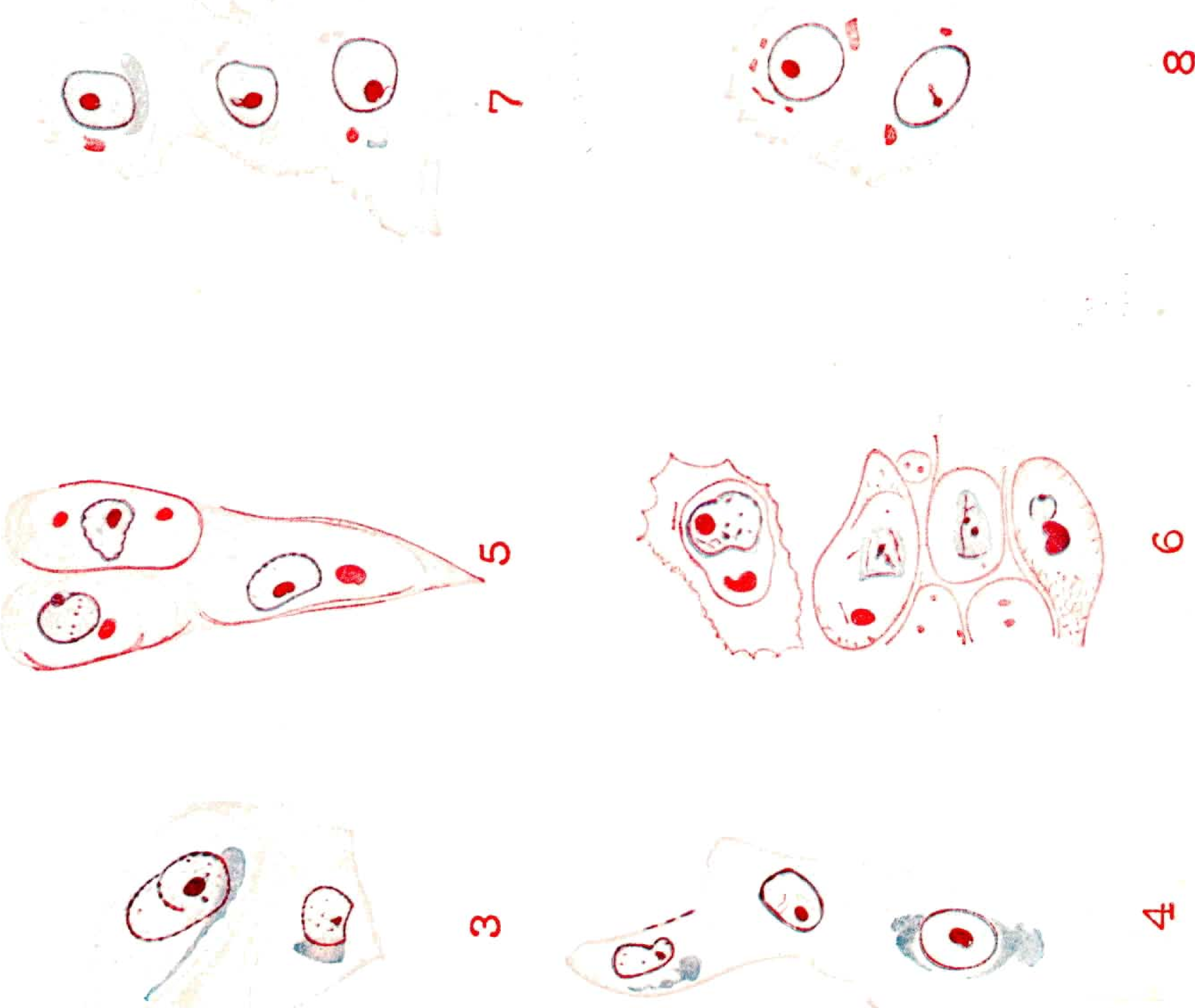

$m$

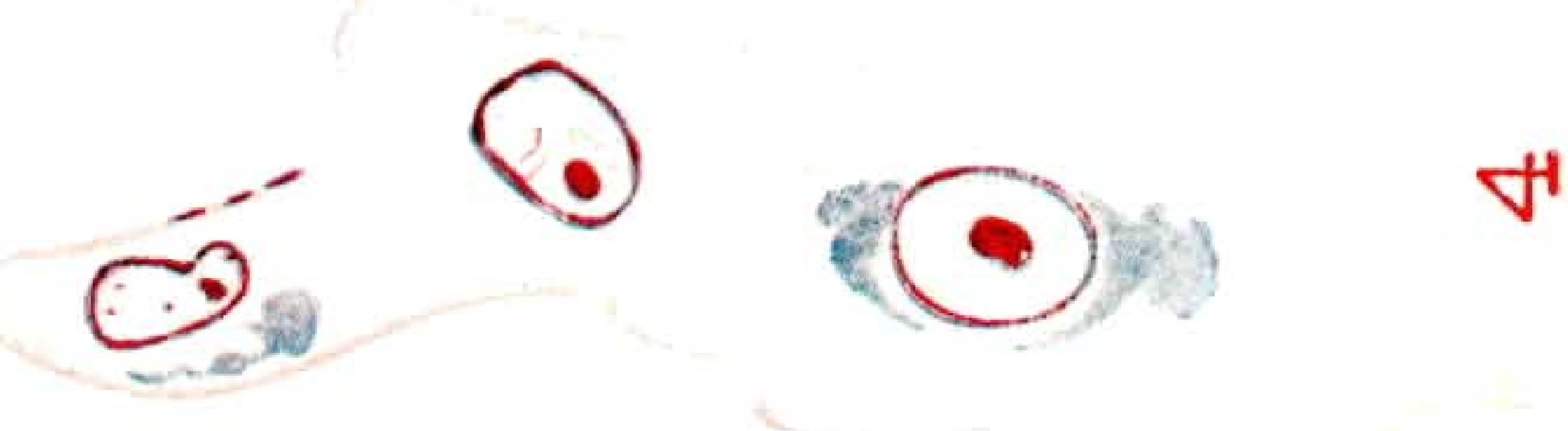

4

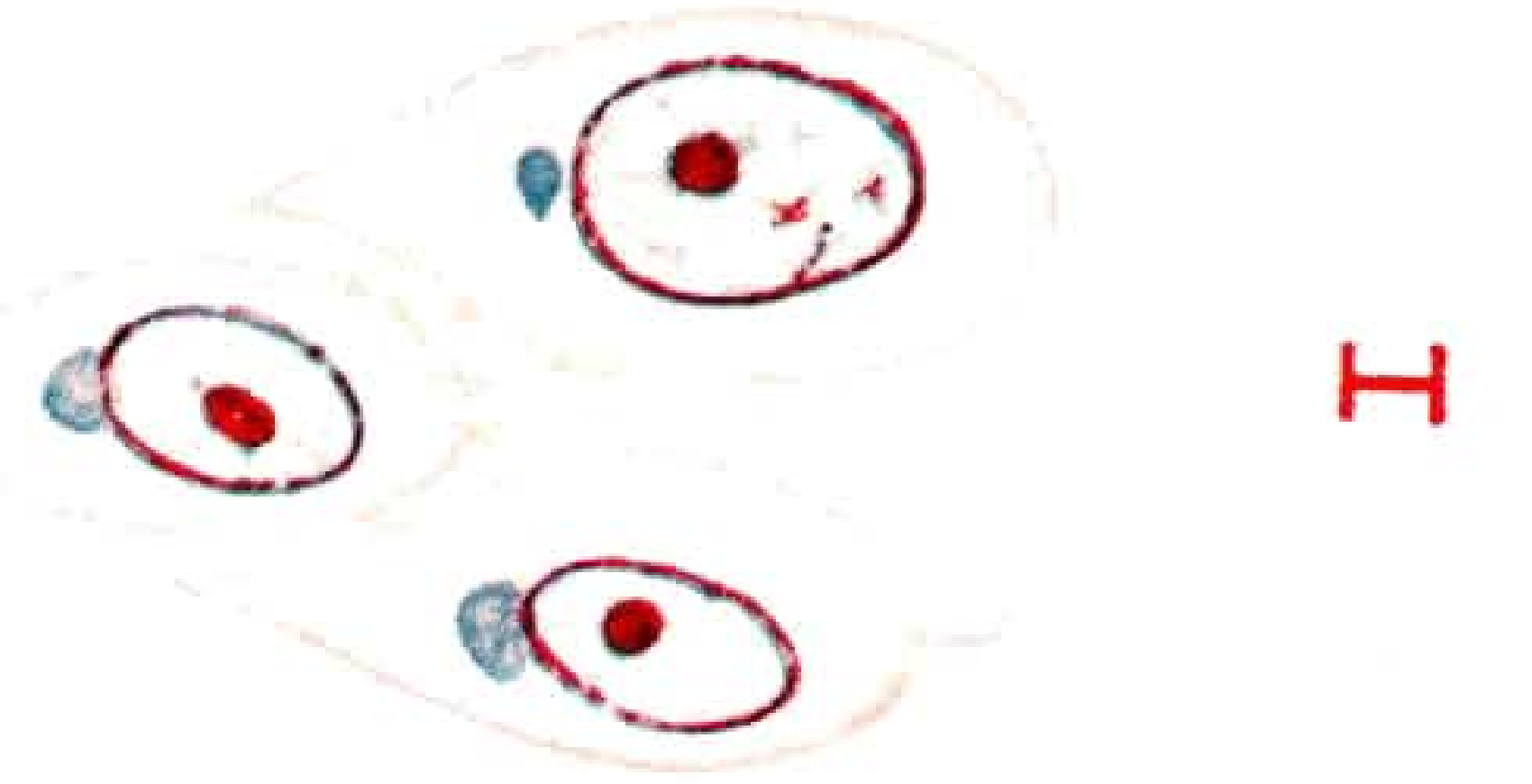

000

N 


\section{Estampa 2}

Fig. 9-Exanthema do alastrim em Macaca mulatta (n.o 1597). Virus de BelloHorizonte, Estado de Minas Geraes, 1933.

Fig. 10 -.. Exanthema do alastrim em Macaca mulatta (n.o 2425). Virus do Estado do Pará, 1936.

Figs. 11 e 12 - Exanthema do alastrim em Macaca mu'atta (n.o 2493). Virus do Estado de São Paulo, 1936. 
MEM. INST. OSWALDO CRUZ

32, 4, DEZ., 1937

EST. 2
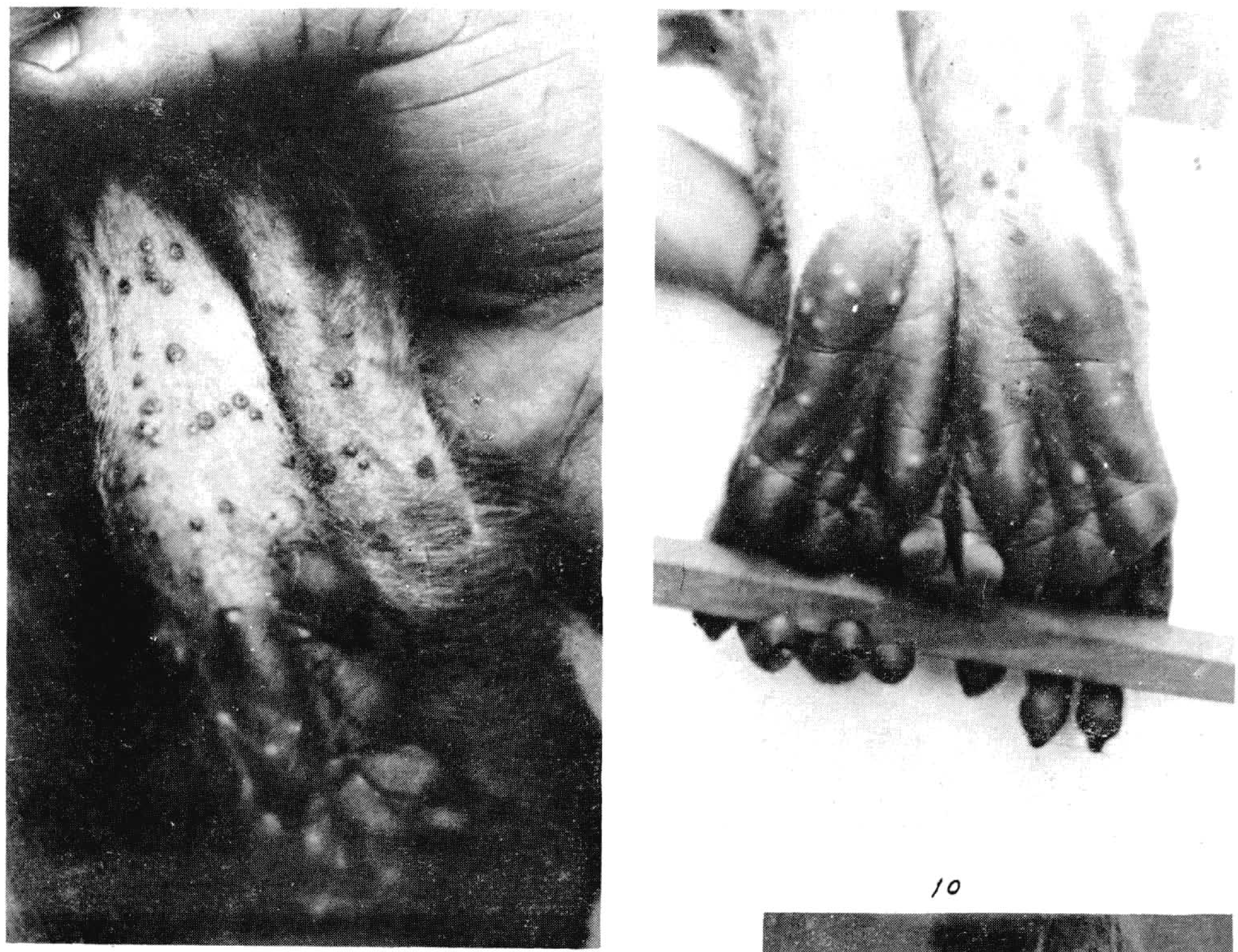

9

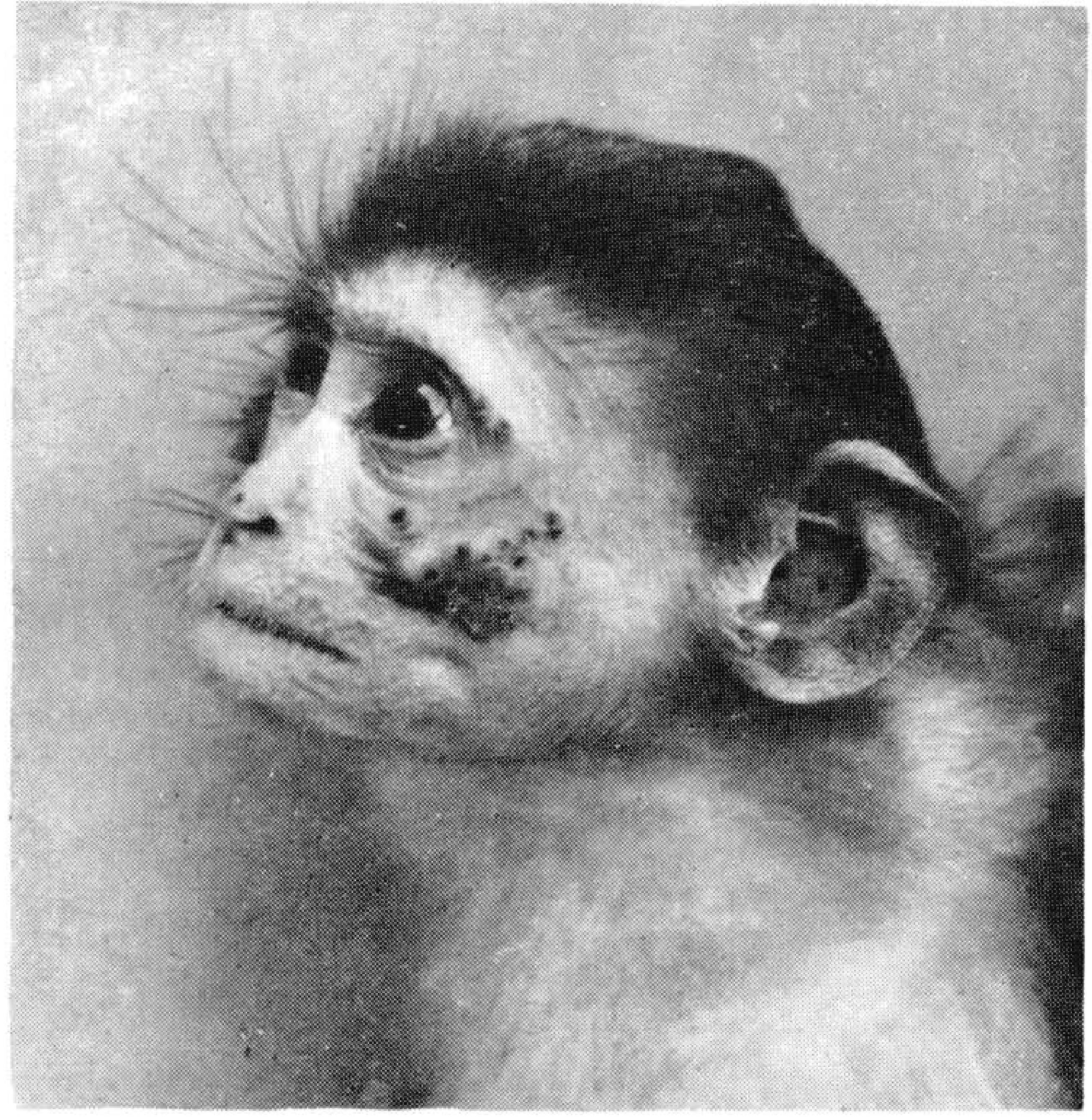

11

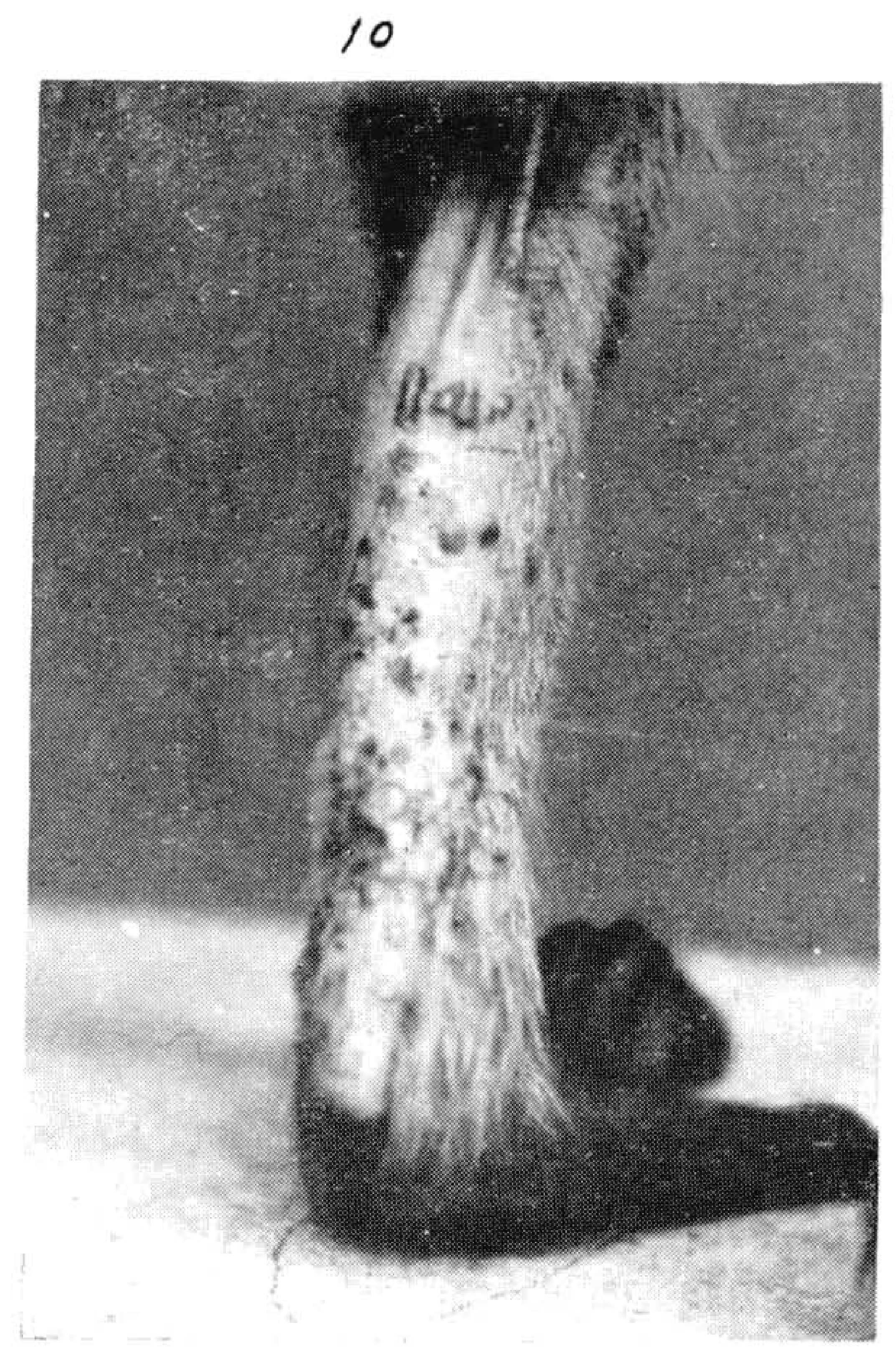

12

Torres \& Teixeira: Methodo para o diagnostico do alastrim. 


\section{Estampa 3}

Fig. 13 - Inelusões cytoplasmaticas do alastrim em cellulas epidermicas de Macaca mulatta (n.o 2425, biopsia 7387). Virus do Estado do Pará, 1936

Fig. 14-Inclusoes cyloplasmaticas do alastrim em cellulas epidermicas de $\mathbf{M a}$ caca mulatta (n.o 2493, biopsia 4929). Virus do Estado de São Paulo, 1936.

Fi⿳⺈. 15 --. Inclusões cytoplasmaticas do alastrim em cellulas epidermicas de $M a$ caca mulatta (n.o 1597, biopsia 3983). Virus de Bello-Horizonte, Estado de Minas Geraes, 1933.

Fïg. 16-Inclusões intranuclear e cytoplasmatica em cellula epidermica de Macaca mulatta (n.o 2493, biopsia 4929). Virus do Eslado de São Paulo, 1936. 
MEM. INST. OSWALDO CRUZ

EST. 3

32, 4, DEZ., 1937

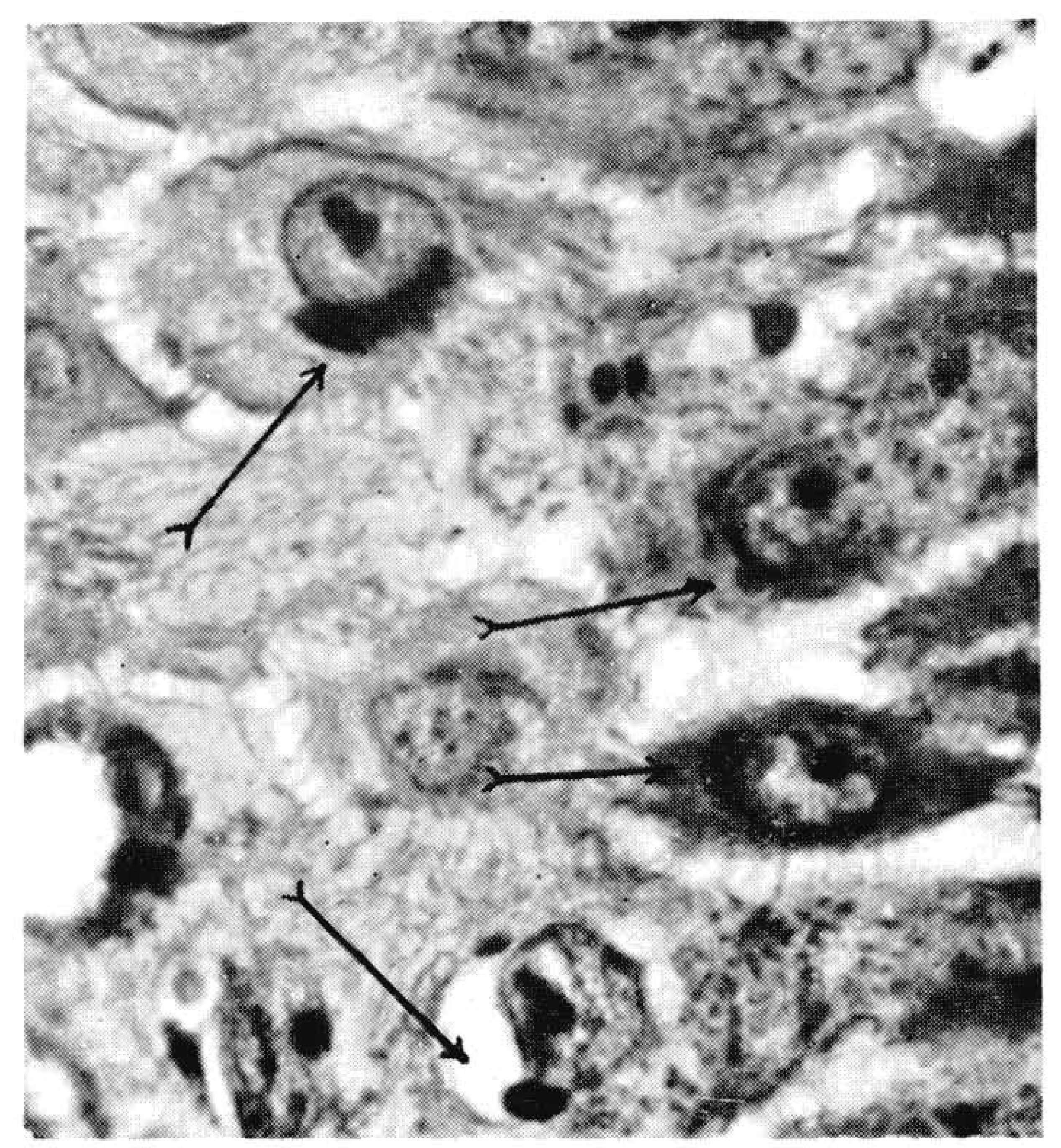

13

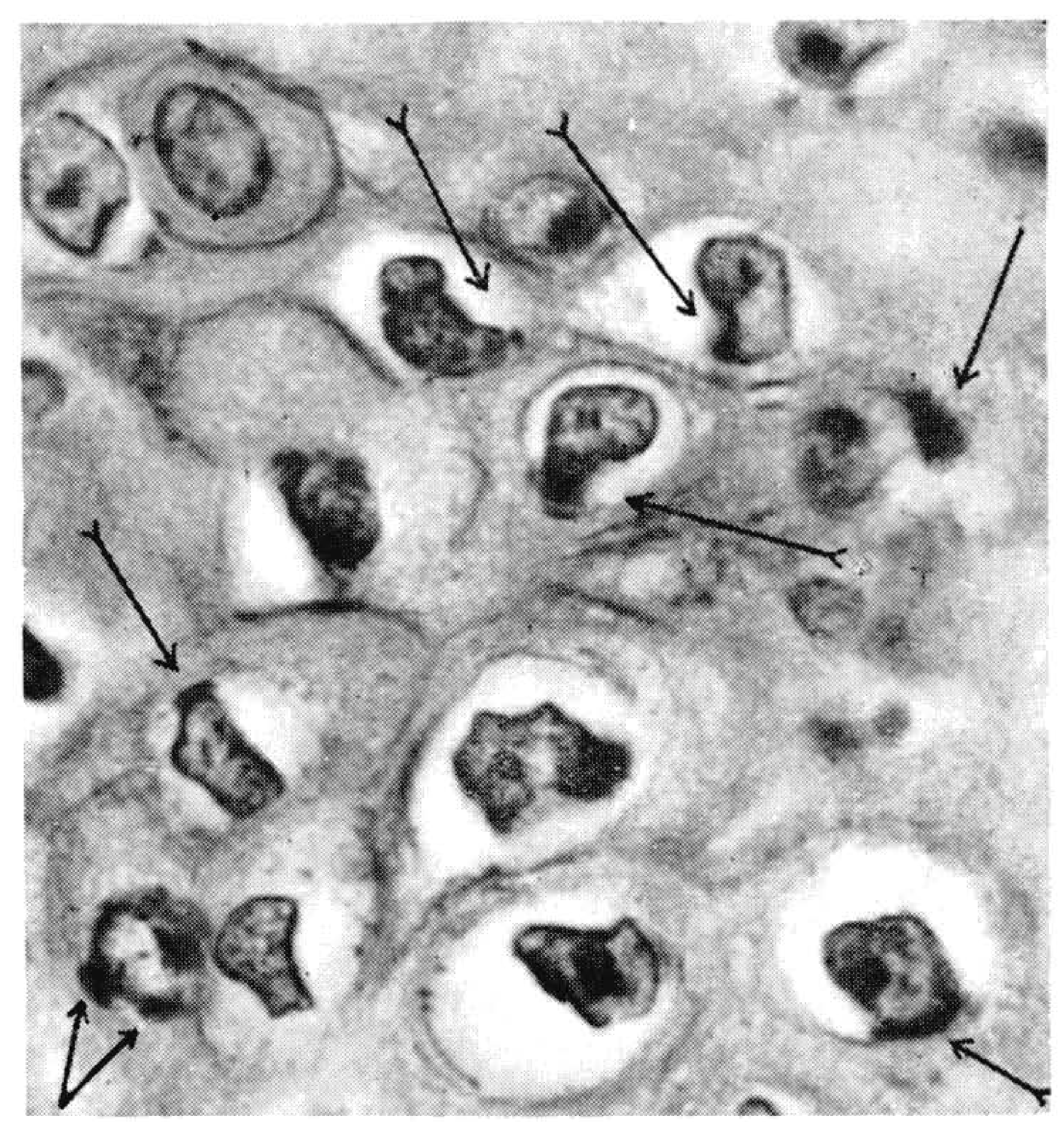

14
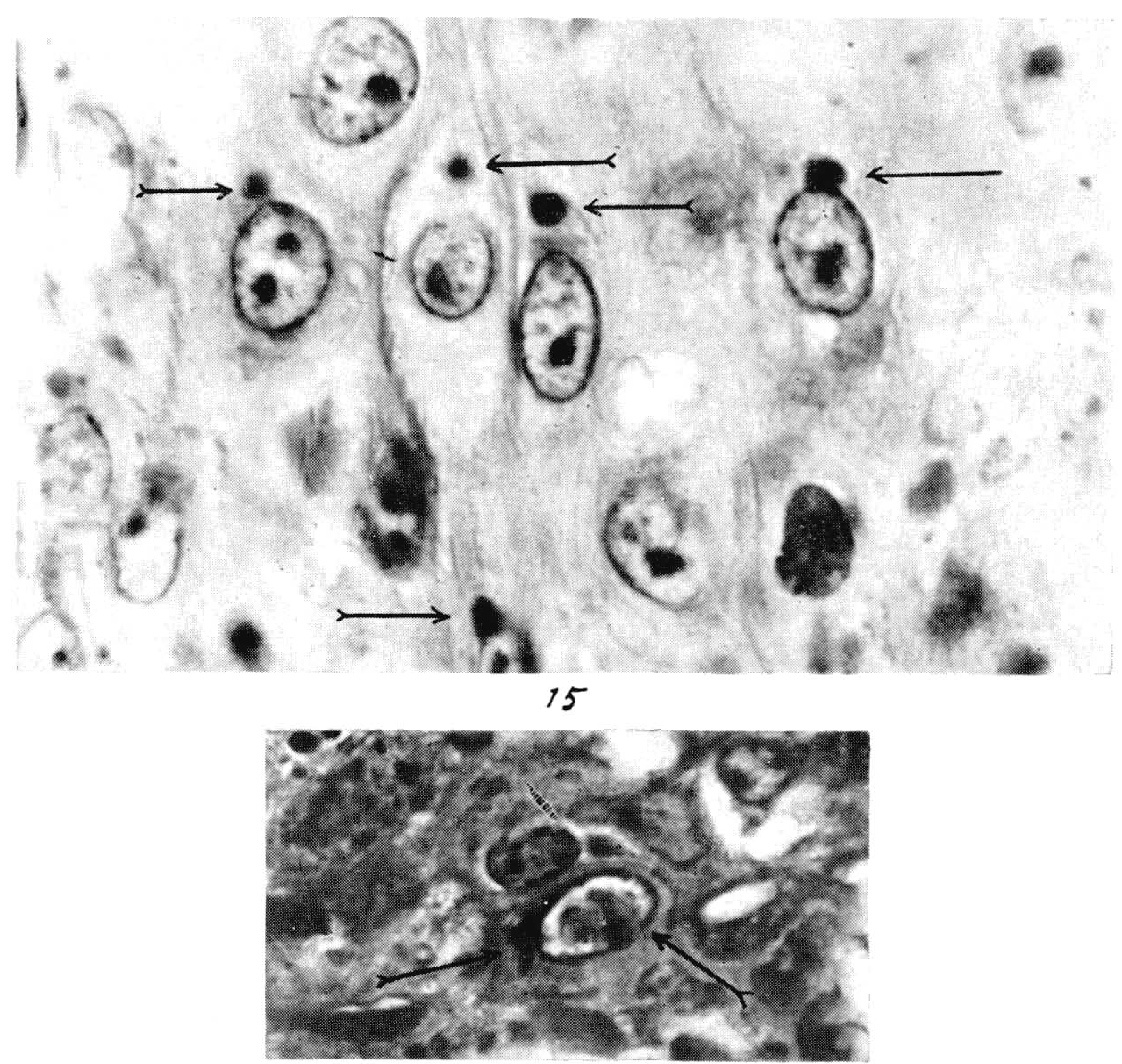

16

Torres \& Teixeira: Methodo para o diagnostico do alastrim. 